\title{
As Origens Históricas do Eletroscópio
}

(The Historical Origins of the Electroscope)

\author{
Alexandre Medeiros \\ Departamento de Física e Matemática, \\ Universidade Federal Rural de Pernambuco, Recife, PE
}

Recebido em 2 de abril, 2002. Aceito em 19 de julho, 2002.

\begin{abstract}
Este trabalho parte do fato de que o ensino da Eletrostática tem se afastado da fenomenologia que lhe deu origem. Investigando-se a história dos eletroscópios, tenta-se mostrar como algumas idéias tão importantes quanto as de carga, potencial e capacidade elétrica tiveram suas origens ligadas ao uso de um tal instrumento. Para além dos importantes detalhes históricos assinalados, a história do eletroscópio revela também algo de inquestionável valor filosófico no ensino da Física: a extensão na qual as observações dos fenômenos elétricos sempre estiveram carregadas de pressupostos teóricos.
\end{abstract}

This paper starts from the fact that the teaching of electrostatics is becoming increasingly apart from the phenomenology in which it roots. Investigating the history of electroscope we try to show how some ideas as important as charge, potential and electric capacity had their origins linked to the use of such an instrument. Beyond the assigned important historical details, the history of electroscope can also reveal us something of unquestionable philosophical value in the teaching of physics: the extent to which the observation of electrical phenomena were always theoretically laden.

\section{Introdução}

O ensino da eletrostática tem sido caracterizado por um crescente afastamento da fenomenologia que envolve este ramo da Física. De fato, analisando-se os livros textos mais antigos, pode-se encontrar um número bem maior de referências a experimentos fundamentais e aos detalhes de funcionamento de certos instrumentos básicos, dentre eles o eletroscópio e o eletróforo. Em lugar de iniciar com o estudo de uma fenomenologia macroscópica observável e a partir dela construir um conhecimento que chegue à natureza microscópica da matéria, os textos mais recentes partem já, de modo postulativo, da natureza atômica da matéria (Scaricabarozzi, 1983; Medeiros \& Lima Jr, 2000). Isso é algo paradoxal, pois os experimentos eletrostáticos estão entre os mais utilizados em museus de ciência, principalmente por alguns dos seus muitos efeitos espetaculares. Este tal descuido, no ensino escolar, em relação às bases observacionais e conceituais da eletrostática traz conseqüências danosas para o ensino e a aprendizagem da eletrostática, fazendo com que os estudantes sejam simplesmente treinados segundo o credo de uma teoria que não conseguem perceber de onde surgiu.

\section{O Eletroscópio no Ensino da Eletrostática}

Relegados a um segundo plano nas abordagens de ensino mais recentes, estes instrumentos eletrostáticos têm sido vistos, geralmente, como artefatos tão simples que pouco teriam a oferecer numa sala de aula. A trivialização desses instrumentos carrega, contudo, um enorme equívoco. Instrumentos de aparências singelas, como um eletroscópio, por exemplo, encerram em suas próprias construções um arsenal de conceitos físicos fundamentais, cuja discussão muito poderia contribuir para uma melhor compreensão da eletricidade. Tome-se, por exemplo, o fenômeno da eletrização por atrito, discutido comumente de forma extremamente superficial nos livros-texto e nas aulas de Física. Deixase de lado, por exemplo, uma análise das condições necessárias para que um processo de atrito possa efetivamente ocasionar uma eletrização (Ainslie, 1967). Não se discutem também, numa etapa mais avançada do curso, quaisquer evidências observacionais que possam evidenciar que a eletrização por atrito depende do potencial de contato (Anderson, 1936). Assim sendo, fica a impressão errônea de que um qualquer atrito faz que uma determinada substância adquira sempre o mesmo tipo de eletrização, a despeito do outro material com o qual tenha sido atritada (Plumb, 1971). 
Nessas condições, o importante estudo da triboeletricidade é completamente deixado de lado, em detrimento das conseqüências nefastas que daí possam advir para a aprendizagem da eletricidade.

Além das questões atinentes à eletrização por atrito, igualmente o fenômeno da indução eletrostática pode ter suas características evidenciadas por uma análise cuidadosa do funcionamento do eletroscópio. Os efeitos inusitados, relacionados à indução eletrostática, que podem ser demonstrados com o auxílio de um eletroscópio, são uma fonte inesgotável de questionamentos a serem debatidos com os estudantes em sala de aula (Spencer, 1958; Jefimenko, 1979). Trabalhos recentes têm evidenciado que atividades experimentais com eletroscópios e eletróforos podem contribuir decisivamente para que os estudantes explorem, de forma construtiva, os conceitos de indução eletrostática e o significado do aterramento (Stewart \& Gallai, 1998).

Apesar de um tanto relegado pelos livros-texto mais recentes, muito tem sido escrito sobre as possibilidades experimentais dos eletroscópios, sobre suas potencialidades educacionais, suas limitações e sobre modificações interessantes a serem introduzidas na sua confecção (Myers, 1990; Edge, 1984; Davies, 1974; Siddons, 1979; Ohriner \& Machtinger, 1969; Steenson, 1975).

Por outro lado, o estudo do desenvolvimento histórico do eletroscópio pode revelar toda uma história de construção de conceitos da eletricidade, como também possibilitar a apreciação do papel por ele desempenhado na criação da Física atômica (Roller \& Roller, 1953; Siddons, 1983). O desenvolvimento de estratégias de ensino, convenientemente relacionadas às demonstrações com eletroscópios em sala de aula, pode, por outro lado, propiciar a discussão de idéias sobre a própria natureza da observação, colocando as descobertas nos seus contextos respectivos históricos e auxiliando a relacionar o conhecimento científico com as suas aplicações práticas (Engelmann, 1983).

O propósito deste trabalho consiste em buscar as raízes históricas do eletroscópio de forma a explicitar com maior clareza o quanto as relações teoriaexperimento estiveram intrinsecamente ligadas na construção dos conceitos embutidos na concepção de um tal instrumento.

\section{Metodologia}

Seguindo os contornos de uma pesquisa histórica, fundada numa preocupação nitidamente educacional, procurou-se construir um quadro geral de informações a respeito da criação e do desenvolvimento do eletroscópio baseado parcialmente em algumas fontes primárias como o De Magnete, de Gilbert, a histórica obra de Sigaud de la Fond e outros vários textos originais reproduzidos por Maggie em seu influente $A$ Source Book in Physics. Foram, igualmente, utilizadas várias fontes secundárias de reconhecido valor acadêmico, devidamente apontadas na bibliografia deste trabalho. O eixo interpretativo das informações coletadas esteve sempre voltado para a explicitação das cargas teóricas presentes nos experimentos realizados e na explicitação dos pressupostos presentes na construção dos novos conceitos como a condução elétrica, a tensão e a indução eletrostática. Desta forma, foi possível identificar, com certa nitidez, as construções dos significados atribuídos pelos diversos personagens envolvidos na história tratada numa vertente metodológica semelhante àquela adotada por Nercessian (1984).

No seio desta investigação residia a firme convicção de que poucas coisas são mais importantes no ensino e na aprendizagem da Física do que uma compreensão da complexa relação entre teoria e experimento (Franklin, 1990).

Assim sendo, o caminho interpretativo das informações coletadas seguiu a linha de um estudo de caso histórico, no qual o mergulho em profundidade na análise das questões colocadas sobrepuja quaisquer preocupações com a abrangência das conclusões dali retiradas (Conant, 1957).

\section{A Evolução Histórica do Ele- troscópio de Gilbert a Cou- lomb}

A maior parte dos instrumentos de medidas da eletricidade foi desenvolvida após 1770. Ao final do século XVIII, existiam vários modelos desses instrumentos, obedecendo a diferentes concepções, dentre os quais destacavam-se as balanças, os eletroscópios e os eletrômetros. Os eletroscópios e os eletrômetros recebiam, respectivamente, essas denominações, conforme estivessem destinados a uma simples avaliação do estado de eletrização dos corpos ou a uma medida mais efetiva desse mesmo estado. Para efeitos práticos, um eletrômetro nada mais é que um eletroscópio provido de uma escala, pelo que a denominação "eletroscópio", será utilizada, neste artigo, de uma forma abrangente. De início, não estava claro se aquilo que podia ser avaliado com os eletroscópios era, de fato, a carga acumulada ou algo mais complexo relacionado ao tal estado de eletrização do instrumento. A evolução histórica dos conceitos veio a esclarecer esta questão ao compreenderse que o eletroscópio, efetivamente, avaliava o que viria a ser denominado, posteriormente, de potencial elétrico. Esta, no entanto, não é uma questão simples, e muitos livros-texto, ainda nos dias atuais, permanecem afirmando, equivocadamente, que o afastamento entre as folhas de um eletroscópio é uma medida da quantidade de carga acumulada nas mesmas.

Os principais motivos propulsores do desenvolvimento dos eletroscópios foram as investigações da ele- 
tricidade atmosférica e as tentativas de medir o rendimento das máquinas eletrostáticas. Por muito tempo, após a época de Gilbert (1544-1603), a eletricidade havia sido produzida apenas pelo atrito de pedaços de âmbar, vidro ou enxofre com materiais como as roupas do pesquisador ou mesmo com as suas próprias mãos. Ainda no século XVII, no entanto, foi criado um novo modo de eletrizar mais vigorosamente os corpos: a máquina eletrostática. Idealizada originalmente por Otto von Guericke, ela consistia, inicialmente, em uma simples bola de enxofre, com um eixo central, montada numa armação de madeira, de modo que podia ser facilmente posta a girar em torno deste eixo. A eletrização era obtida originalmente pelo atrito contínuo das mãos contra a esfera, processo esse que seria, posteriormente, aperfeiçoado com o uso de pedaços de lã. Essa primitiva máquina de atrito foi sucessivamente aperfeiçoada, durante todo o século XVIII, por indivíduos como Hauksbee, Musschenbroek, Nollet, Tibérius Cavallo, Beccaria, Canton, Priestley, Franklin, Nairne, Marinus van Marum, e muitos outros. A importância e efeitos no desenvolvimento da eletrostática foi enorme e não deve jamais ser subestimada. Uma análise, porém, dos detalhes e princípios de seu funcionamento está fora do escopo deste presente trabalho, podendo, entretanto, ser encontrada em algumas obras aqui referenciadas (Hackmann, 1978; Dibner, 1957; Thompson, 1895).

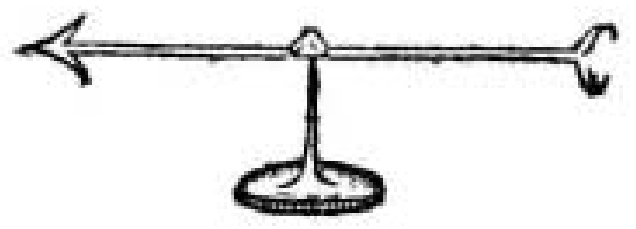

Versorium de Gilbert.

Apesar do sucesso alcançado pelas máquinas eletrostáticas no século XVIII, as tentativas feitas à época para produzir padrões de medidas das eletrizações, assim como a busca de técnicas padronizadas para efetuar tais medidas, não obtiveram, de início, o êxito esperado. O principal motivo deste insucesso foi a falta de uma clareza, à época, acerca da totalidade dos fatores envolvidos que influenciavam o funcionamento daqueles instrumentos. Os conceitos físicos envolvidos não haviam sido ainda devidamente identificados (Hackmann, 1978). "A quantificação da teoria física pressupõe a existência de conceitos apropriados, expressáveis matematicamente, e simples de serem testados e medidos. $O$ coração do processo está na construção dos conceitos. Como mostra o sofrido aparecimento da noção de carga localizada, mesmo os conceitos mais simples podem ser muito difíceis de serem encontrados. A quantificação efetiva da eletrostática requereu, além do conceito de uma carga isolada (Q), os conceitos de capacidade $(C)$ e de potencial $(V)$, assim como a redução das forças macroscopicamente mensuráveis, a forças microscópicas, assumidas como atuando entre os elementos de carga elétrica. Esses ingredientes já estavam à mão por volta do final dos 1780" (Heilbron, 1982, p. 218).

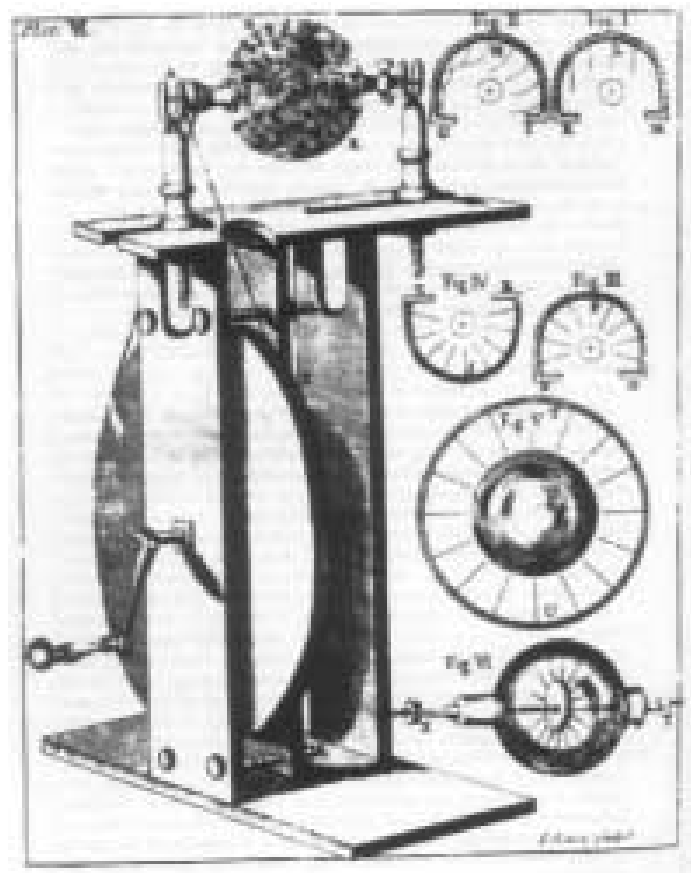

Máquina eletrostática de Hauksbee.

Por longo tempo, havia ocorrido um descompasso entre as necessidades de avanços na questão das medidas elétricas e uma melhor compreensão das quantidades a serem medidas. Uma retrospectiva histórica dos melhoramentos introduzidos nos instrumentos de medidas elétricas pode dar uma idéia do quanto o aperfeiçoamento de tais artefatos estava ligado ao desenvolvimento conceitual na eletricidade.

O mais antigo eletroscópio foi o "versorium", de Gilbert, ilustrado em seu livro "De Magnete" (1600), que consistia de uma agulha montada num pivô, lembrando uma bússola. Gilbert foi um dos pioneiros nas investigações dos fenômenos elétricos e na identificação de uma natureza própria para a eletricidade, distinta do magnetismo. A agulha do versorium era feita inicialmente de um metal claro, não magnetizado, equilibrada em um pino colocado no ponto central da mesma. Em outras versões do versorium, Gilbert substituiu a agulha metálica por um pedacinho de palha. O versorium permitiu a Gilbert a realização de estudos muito mais sensíveis que aqueles feitos até então pelos seus antecessores, como Petrus Peregrinus e Robert Norman. Gilbert investigou várias substâncias que atraíam a palha, compilando uma lista enorme de materiais que poderiam ser eletrificados por atrito, denominando-os de 
"elétricos". Ele notou, ainda, que a atração elétrica diferia da magnética pelo fato de que não havia nenhum pólo nos objetos eletrificados (Gilbert, 1958). Com a construção do novo conceito de materiais "elétricos", a eletricidade deixou de ser vista como sendo uma propriedade de um único corpo, ou de um certo par de corpos, para passar a ser encarada como uma propriedade de vários corpos na natureza.

Otto von Guericke, ainda no século XVII, e Stephen Gray, já no século XVIII, utilizaram penas de aves para indicar as eletrificações. Um outro precursor do eletroscópio foi o método rudimentar, inventado por Francis Hauksbee, ainda em 1705. Tal método consistia na utilização de vários pedaços de linha suspensos, lado a lado, na extremidade de uma barra cilíndrica de vidro ou na superfície interior de uma esfera oca, igualmente de vidro, de tal modo que as linhas ficavam penduradas para baixo com suas extremidades afastadas, aproximadamente, uma polegada do vidro. Quando o vidro era eletrificado por atrito, as linhas reordenavam-se passando todas a apontarem radialmente em direção ao mesmo. Os vários experimentos realizados por Hauksbee com as linhas orientadas eletricamente estimularam as discussões sobre os "eflúvios" ou emanações da virtude elétrica. (Gamow, 1988; Home, 1992).

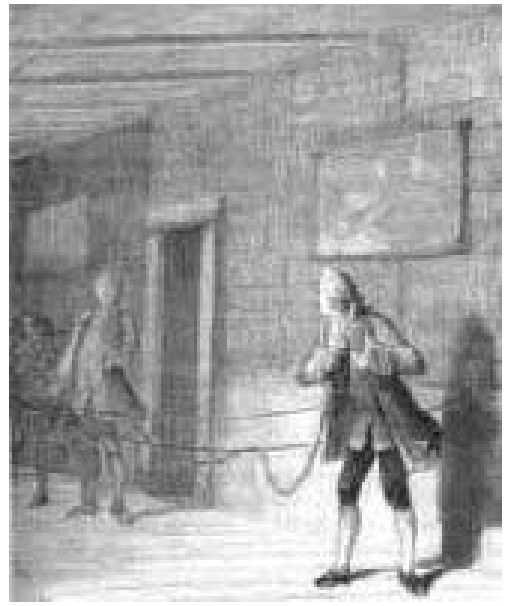

Stephen Gray \& Desaguliers_ experimento de condução.

Elaborando a idéia de Hauksbee, de utilizar várias linhas dependuradas, Stephen Gray utilizou, já na década dos 1740, um único par de linhas de seda ou um par de penas, para avaliar, através da divergência angular entre elas, as intensidades das eletrizações produzidas. O conhecido eletroscópio pendular de bolinha de sabugueiro tem, portanto, sua origem nas linhas dispostas por Hauksbee em seus tubos e globos de vidro, assim como nas penas e nas linhas dependuradas por Stephen Gray nos seus condutores metálicos. Mantendo uma pena pendurada próximo à extremidade de um tubo metálico, cuja outra extremidade tocava num globo de vidro eletrizado, Gray constatou que a pena era atraída em direção ao tubo e logo após repelida, ao tocar no mesmo (Leon, 1988). O processo de detecção da eletricidade, com a utilização de linhas, utilizado por Gray foi descrito pela primeira vez por Wheeler, um amigo e colaborador nos seus experimentos. Os experimentos de Gray consistiam em tomar um corpo eletrizado e tocálo com outros corpos bastante extensos, como barras e fios, observando, com seu eletroscópio rudimentar, em que condições os efeitos elétricos apareciam ao longo de tais corpos extensos. Esses experimentos contribuíram para a descoberta da condução da eletricidade. Pensando na eletricidade como um fluido, Gray observou que ela viajava através de alguns corpos e não de outros. Rejeitou, assim, os velhos conceitos de "elétricos" e "não elétricos", introduzidos por Gilbert, isto é, aqueles corpos, respectivamente, que geravam e aqueles que não geravam eletricidade. Gray passou a adotar, então, uma distinção entre os corpos que conduziam a eletricidade (os antigos não elétricos) e os que a isolavam (os antigos elétricos), denominando-os respectivamente, de condutores e isolantes.

Essa não é uma questão meramente semântica, como pode parecer à primeira vista, mas carrega, em verdade, uma nova conceituação sobre a própria natureza da eletricidade. Com Gray, a eletricidade deixa de ser vista, simplesmente, como uma "virtude" que podia ser transmitida, para ser tida como algo substancial que podia viajar através da matéria. A própria existência independente da eletricidade é que estava sendo conceitualmente construída nessa nova denominação. (Canby, 1966; Anderson, 1968; Bernal, 1973).

A moderna filosofia da ciência assinala que as observações são carregadas de pressupostos teóricos. A história da eletricidade fornece ótimas ilustrações de uma tal assertiva. Confrontem-se, por exemplo, as observações de Guericke com as de Gray a respeito da natureza da eletricidade e da existência ou não de um fluxo elétrico. É essencial perceber que a imagem de algo fluindo corresponde à construção de um novo modelo mental que deu novos rumos ao estudo da eletricidade. Para que se tenha uma idéia da importância de uma tal construção conceitual e da sua interferência naquilo que poderia ser observado, bastaria mencionar que Guericke, ainda no século XVII, havia feito alguns experimentos com a sua máquina eletrostática, semelhantes aos que viriam a ser realizados por Gray no século seguinte, sem, contudo, realizar as mesmas observações. Guericke, efetivamente, observara que objetos eletrificados podiam transferir parte da sua "virtude elétrica", ou seja da sua "capacidade de atrair", denominada de "carga", para outros objetos não eletrificados. Com uma bola de enxofre Guericke conseguiu carregar uma outra, mas não deduziu daí, ou seja, "não observou" a "condução elétrica", o fluxo de eletricidade, pois a eletricidade não era reconhecida como algo concreto, que tivesse uma existência independente. O modelo mental de Guericke da "eletricidade como uma virtude", uma "vis", permitia-lhe observar apenas que uma bola to- 
cada por outra já eletrizada ganhava a referida virtude elétrica, mas ele não conseguia imaginar nada passando entre elas, não observando, assim, nenhuma condução elétrica.

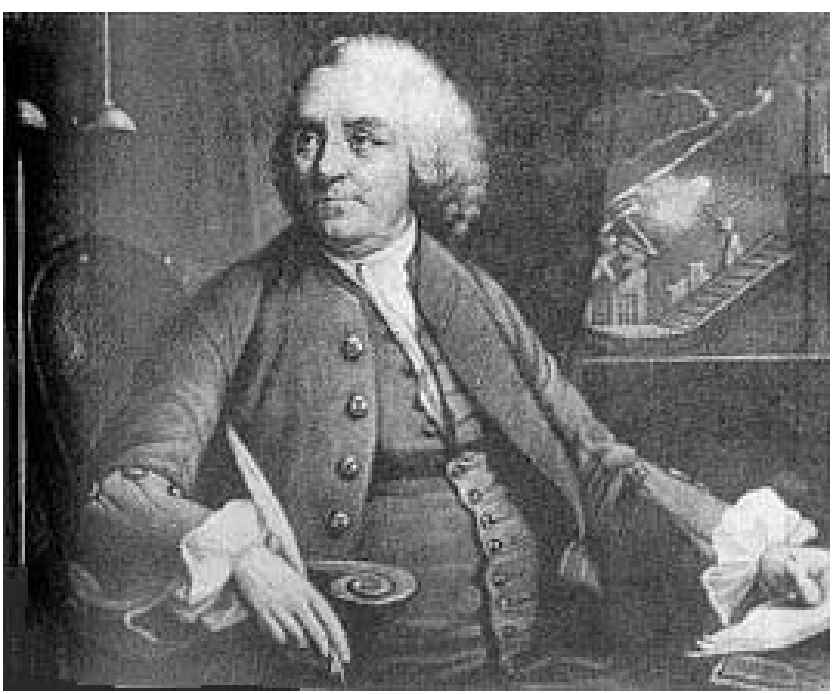

Franklin - pêndulo eletrostático e sua máquina elétrica.

Certamente, mesmo para Gray, ainda não parecia claro aquilo que estava sendo medido com a deflexão angular entre as linhas de seda (Heilbron, 1982). Gray, no entanto, teve um "insight" que viria a frutificar em trabalhos posteriores aos seus: a eletricidade não parecia preencher todo o corpo dos "não elétricos" (condutores, em nossa terminologia moderna). Tomando-se dois cubos de carvalho, de mesmas dimensões, um cheio e um outro oco, carregados da mesma maneira, podiase observar que causavam deflexões idênticas entre as linhas de seda. Olhando de um ponto de vista mais recente, pode-se perceber que Gray estava diante do que poderia ser interpretado, atualmente, como uma evidência de que os potenciais eletrostáticos dos dois cubos eram idênticos e de que, em última instância, a informação fornecida pela deflexão das linhas pode, efetivamente, ser associada a este potencial. Nada disso, no entanto, foi observado por Gray. Faltou-lhe a ferramenta teórica do conceito de potencial para que algo desse tipo pudesse vir a ser observado. Assim como faltara a Guericke a idéia da eletricidade como algo com uma existência independente, e não apenas como uma virtude, para poder observar o fenômeno da condução elétrica, faltou a Gray o conceito de potencial para que pudesse observar o que mediam as deflexões entre as linhas de seda nos fenômenos por ele estudados. Esta complexa imbricação teoria-observação, na análise de um fenômeno, é uma das coisas mais importantes para aqueles que ensinam Física. Afinal, de acordo com o sentido grego da palavra, "fenômeno é aquilo que pode ser visto".

À mesma época, François Du Fay utilizou, na França, o mesmo esquema de linhas indicadoras de
Gray nos seus experimentos, e isso o levou a formular a idéia da existência de dois tipos diferentes de fluidos elétricos. Benjamin Franklin, por seu lado, em seus influentes estudos sobre a eletricidade, adotaria um sistema semelhante ao de Gray para avaliar eletrizações. Tais estudos conduziriam Franklin, porém, ao modelo de um único fluido elétrico, em oposição ao modelo de dois fluidos elétricos proposto por Du Fay. Franklin usaria, também, como indicador de eletrização, o comprimento da centelha produzida, por exemplo, por uma garrafa de Leiden, ao ser descarregada.

As primeiras tentativas concretas de construção de instrumentos para medirem as eletrizações, os eletroscópios, são efetivamente dessa época. Dentre tais tentativas destacam-se os trabalhos dos franceses d'Arcy e Le Roy. Em 1752, o abade Nollet, assistente de Du Fay e responsável pela educação da família real francesa, adotou um sistema, muito semelhante ao de Gray, que consistia em dois fios suspensos a partir de uma mesmo ponto e que formavam entre si um determinado ângulo ao serem carregados. Nollet acrescentaria, logo depois, ao método das linhas de seda criado por Gray, uma escala circular (uma espécie de transferidor) e um sistema ótico de projeção, produzindo, assim, o primeiro eletrômetro do qual se tem conhecimento. Seu aparelho, no entanto, apresentava ainda, assim como o sistema de Gray, sérios problemas de fuga da eletricidade e não era, deste modo, um aparato sensível.

Giovanni Beccaria, um importante físico de Turin, interpretou as deflexões entre as linhas de seda de um modo diferente. Em vez de tomar o ângulo de deflexão $\alpha$, como de costume, para indicar a força elétrica, tomou o sen $\alpha$ como uma medida desta mesma força. Considerando-se que o ângulo formado entre a força elétrica e o deslocamento horizontal da lâmina é o complemento do semi-ângulo de deflexão $\alpha / 2$, pode-se notar o quão próximo esteve Beccaria de enfocar a decomposição de tal força elétrica naquela direção horizontal: $\mathrm{F} \cos \alpha / 2$. Embora o conceito de trabalho mecânico não estivesse ainda estabelecido, o que viria a se dar apenas a partir do início do século XIX (Harman, 1985), as peças necessárias para o desenvolvimento da idéia de trabalho realizado pela força elétrica e a energia potencial a ele associada já começavam a surgir em tais experimentos. Avizinhava-se, portanto, o esclarecimento do que estaria, efetivamente, sendo medido pelo eletroscópio.

Beccaria, além disso, preocupado com as questões ligadas à eletricidade atmosférica, repetiu o célebre experimento da pipa, realizado anteriormente por Franklin, inventando, em conexão, um novo instrumento de medida. Seu aparelho consistia em dois fios pontiagudos, um deles ligado à extremidade inferior de um alto condutor metálico, mantido na vertical, enquanto o outro era aterrado ao chão. No espaçamento entre as extremidades pontiagudas dos dois fios eram produzidas centelhas. Colocando-se uma tira de papel, movida 
por um mecanismo de relojoaria, entre essas extremidades, obtinha-se uma marcação dos furos provocados pelas centelhas. O tamanho e a frequência desses furos forneciam um registro gráfico da atmosfera elétrica acima do instrumento (Dibner, 1957).

Richmann introduziu no eletroscópio de linhas um condutor fixo em lugar de uma das linhas, e passou a ler $\alpha / 2$ numa escala em formato de quadrante. As perdas e a imprecisão do método de linhas foram minimizadas com o aperfeiçoamento introduzido por John Canton, em 1754 (Wightman, 1951). Atento ao "poder das pontas", evidenciado pelo pára-raios de Franklin, Canton colocou pequenas bolinhas de sabugueiro envelhecido, ou cortiça, nas extremidades das linhas, reduzindo, assim, consideravelmente as fugas e aumentando, a sensibilidade do aparelho, tornando-o assim mais útil e mais confiável (Bauer, 1960). Uma mudança, aparentemente tão simples, carregava, em verdade, a motivação de uma nova abordagem conceitual, já vislumbrada por Gray nos experimentos com os blocos de carvalho, acima descrita. Os aperfeiçoamentos introduzidos por Canton no eletroscópio permitiram-lhe investigar a natureza da indução eletrostática, constatando que a aproximação de um corpo carregado de um condutor neutro induzia o aparecimento do tipo oposto de carga no lado do corpo neutro mais próximo do corpo originalmente carregado, ou indutor. Ao mesmo tempo, no lado oposto do corpo inicialmente neutro, ou induzido, aparecia uma carga igual e de mesmo tipo da do indutor. Parecia agora claro, para Canton, o fenômeno já anteriormente observado, mas não compreendido, de que, ao afastar-se o indutor, o induzido voltava a ficar neutro. Os sinais opostos e as quantidades aparentemente idênticas das cargas surgidas, assim como a posterior neutralização do induzido, evidenciadas com o seu eletroscópio, levaram-no a conjecturar, baseado no modelo de dois fluidos de Du Fay, sobre uma mera separação de cargas préexistentes no corpo que recebia a influência elétrica.

Tibérius Cavallo, em Londres (1770), construiu um eletroscópio com fios de prata pendurados de uma haste metálica, adicionando bolinhas de sabugueiro nos seus terminais e encerrando o conjunto num vaso de vidro com folhas metálicas finas envolvendo as suas paredes. A haste metálica projetava-se para cima do vaso de vidro com uma pequena esfera em sua extremidade superior. O eletroscópio começava a tomar forma. Pouco tempo depois, Volta construiria um eletrômetro que utilizava dois pequenos pedaços retos de palha suspensos a partir de um mesmo ponto por meio de uma junta bastante móvel (Sigaud de la Fond, 1775).

Em 1772, William Henley criou uma versão mais operacional do modelo de Richmann, que viria a substituir, a partir de então, na Inglaterra, os eletroscópios tradicionais de bolinhas de sabugueiro. Seu instrumento, o "eletrômetro de quadrante", consistia em um eletroscópio de Richmann com bolinhas de sabu- gueiro, em lugar, simplesmente, das linhas. No final do século XVIII, eram já utilizados, nas experiências de indução, por exemplo, diversos tipos de eletroscópios e eletrômetros, dentre os quais o criado pelo reverendo Abraham Bennet, um aperfeiçoamento do aparelho de Tiberius Cavallo, e que viria a se tornar o mais conhecido deles. (Forbes \& Dijksterhuis, 1963; Turner, 1927).

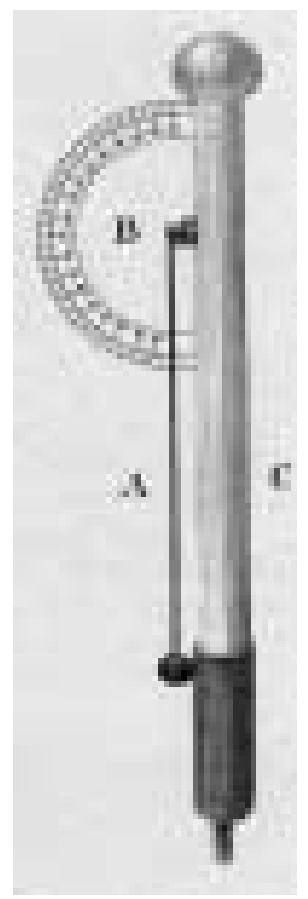

Eletrômetro de quadrante.

Abraham Bennet publicara na Philosophical Transactions, da Royal Society de Londres, de 1787, duas invenções de grande importância. Uma delas era o "eletroscópio de folhas de ouro", que seria aperfeiçoado, logo em seguida, por William Hasledine Pepys, tornando-se, desde então, o mais preciso detector de eletricidade disponível à época. Esse instrumento, bem mais sensível que o seu antecessor de linhas, daria um enorme impulso nas pesquisas sobre a eletricidade.

O outro instrumento, proposto por Bennet, era o "duplicador elétrico", um artefato que permitia, atuando por indução eletrostática, passar de uma carga pequena para uma carga bem maior (Meyer, 1977). Esse duplicador estava baseado num outro aparelho simples e revolucionário, criado por Alessandro Volta em 1775 e por ele mesmo aperfeiçoado em 1782: o "eletróforo" (Canby, 1966; Thompson, 1895).

O eletróforo foi, para Volta e para os seus contemporâneos, um instrumento de usos múltiplos. Seu funcionamento está baseado no princípio da indução eletrostática. Era utilizado basicamente com a finalidade de produzir grandes eletrizações, acumuladas, por exemplo, em garrafas de Leyden, mas servia também 
para a avaliação das eletrizações obtidas evidenciadas pelos comprimentos das centelhas por ele produzidas. O seu desenvolvimento está intimamente ligado à construção do conceito de tensão elétrica, que no século XIX seria identificado com a função potencial. A complexidade do funcionamento, entretanto, foge ao escopo deste trabalho.

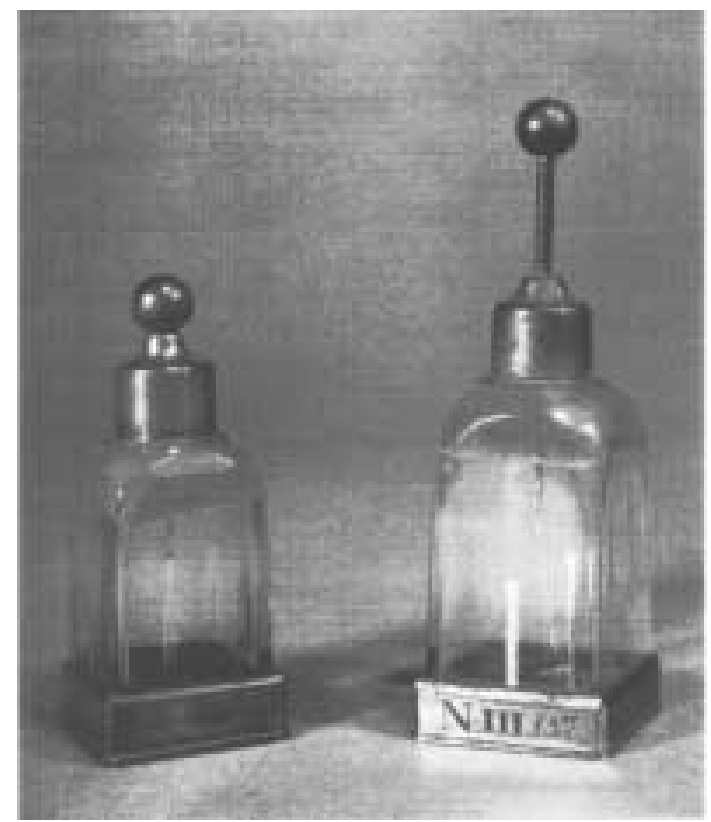

Eletroscópios de folhas de ouro de Bennet.

O eletróforo seria o ponto de partida para uma nova geração de máquinas eletrostáticas, que substituiria as máquinas de atrito, até então utilizadas: as máquinas de indução, conhecidas à época como "máquinas de influência". O "duplicador de Bennet" foi a primeira tentativa de automatizar as funções do eletróforo de Volta, ou seja, a primeira máquina eletrostática de indução.

$\mathrm{O}$ "eletroscópio de folhas de ouro", de Bennet, por outro lado, pode ser tido como um exemplo do desenvolvimento da compreensão do papel desempenhado pelos condutores nos instrumentos de medidas elétricas. A incorporação de folhas de ouro ao instrumento não deve ser vista como o resultado de uma tentativa qualquer de substituição do tipo de folhas utilizado. O ouro, assim como a prata antes utilizada por Tiberius Cavallo, é um elemento muito valioso para ser incorporado, sem maior compromisso, em meros procedimentos de tentativas e erros. A utilização do ouro é, antes de tudo, um reconhecimento do seu papel desempenhado como um excelente condutor.

Em conexão com o eletroscópio de folhas de ouro de Bennet, deveria ser mencionado que, ao final do século XVIII, vários outros eletroscópios e eletrômetros estavam igualmente em uso ou em desenvolvimento. Certo é que todos esses instrumentos estavam já sendo utilizados na segunda metade do século XVIII. Daniel Gralath, de Dantzig, por exemplo, por volta desta mesma época, havia construído uma espécie de " balança elétrica", precursora de uma série de instrumentos semelhantes que culminariam no célebre instrumento de Coulomb.

Já em 1749, Le Roy e d'Arcy haviam inventado um primeiro instrumento capaz de medir forças elétricas, o "eletrômetro-aerômetro". O referido aparelho dispunha de um flutuador e uma haste imersos na água e encimados por um prato. Ao aproximar-se deste prato um segundo prato, ligado a uma máquina eletrostática, produzia-se uma indução elétrica que fazia o aerômetro emergir. Colocando-se pesos sobre o prato do aerômetro, conseguia-se restituir o instrumento à sua posição original. Isso dava uma idéia do valor da força elétrica, agora equilibrada pelo peso disposto sobre o prato do instrumento. Já em 1760, Daniel Bernoulli utilizou tal artefato para determinar o modo como as forças elétricas variavam em função da distância entre os pratos. Suas medidas apontaram na direção da existência de uma relação do tipo inverso do quadrado da distância. A complexidade do fenômeno em estudo, no entanto, aliado à ausência de certos conceitos fundamentais que permitissem uma melhor interpretação, contribuiu decisivamente para que os seus resultados não fossem tidos como evidências suficientemente convincentes de uma tal relação matemática (Bauer, 1960).

O mais importante de todos os instrumentos de medida da eletricidade, surgidos ao final do século XVIII, foi a "balança de torção", apresentada em 1784 por Charles Augustin Coulomb (1736-1807). Para disputar, entretanto, a primazia desta invenção, cabe salientar que o reverendo John Michell, cujo nome é frequentemente mencionado em conexão com a história do magnetismo, havia descrito, anteriormente, uma balança de torção semelhante que viria, logo após, a ser utilizada por Henry Cavendish na determinação da densidade média da Terra. Coulomb, no entanto, parece ter sido, efetivamente, o primeiro a utilizar uma tal balança para determinar as leis dos inversos dos quadrados que regem as forças elétricas e magnéticas. Essa lei havia sido anunciada, para as forças magnéticas, por Johann Tobias Mayer em Goettingen em 1760 e para as forças elétricas por Cavendish em 1762, mas em cada um dos casos apenas com evidências parciais. O uso da balança de torção por Coulomb marca o inicio dos trabalhos quantitativos na eletricidade e no magnetismo e o final de um acelerado período evolutivo nos trabalhos exploratórios com o eletroscópio.

\section{Conclusões}

Embora os aparelhos de medidas elétricas tenham experimentado um enorme avanço durante o século XIX, avanço este impulsionado pelo desenvolvimento conceitual da eletricidade, a seqüência histórica deste desenvolvimento não fez com que os eletroscópios, instrumentos mais rudimentares, viessem a ser esquecidos. Ainda 
que não mais ocupando a cena principal, mas atuando como coadjuvantes, a utilização dos eletroscópios prossegue na história da Física com alguns aperfeiçoamentos menores, mas com marcantes contribuições nos estudos da estrutura atômica realizados no final do século XIX e no início do século XX. A utilização prática dos eletroscópios, simplesmente reajustada aos novos tempos, só seria secundada pelo papel originalmente desempenhado por eles na construção de idéias mais claras sobre os conceitos de carga, potencial e capacidade elétrica. Tal importância parece justificar a necessidade de repensar-se as muitas formas de utilização de um tal instrumento, ainda hoje, nas aulas de Física. Para além dos aspectos meramente demonstrativos possibilitados por este aparelho, estão sobretudo os pressupostos teóricos nele contidos, apontados do decurso evolutivo histórico desse instrumento, que, se bem trabalhados, podem vir a se constituir em poderosas ferramentas heurísticas na reconstrução dos conceitos em sala de aula.

\section{Referências Bibliográficas}

AINSLIE, D. What are the Essential Conditions for Electrification by Rubbing? American Journal of Physics 35, p.535-537, 1967.

ANDERSON, D. El Descubrimiento del Electron. México: Editorial Reverté, 1968.

ANDERSON, S. An Experiment to Demonstrate that "Friction" Electricity Depends on Contact Potential. American Journal of Physics 144, 1936.

BAUER, E. A Eletricidade e o Magnetismo no Século XVIII. In René Taton (org). História Geral das Ciências. São Paulo: Difusão Européia do Livro, 1960. BERNAL, J. The Extension of Man: A History of Physics Before 1900. Frogmoe, St Albans, England: Granada Publishing Limited, 1973.

CANBY, E. História da Eletricidade. Lisboa: Livraria Morais Editora, 1966.

CONANT, J. Harvard case Histories in Experimental Science. 2 vols. Cambridge: Harvard University Press, 1957.

DAVIES, G. An Electronic Gold Leaf Electroscope. Physics Education. 9, n.6, p.393-398, Sep 1974.

DIBNER, B. Early Electrical Machines. Norwalk, Connecticut: Burndy Library, 1957.

EDGE, R. String and Sticky Tape Experiments: Electrostatics with Soft-Drink Cans. Physics Teacher, 22, n.6, p.396-98, Sep 1984.

ENGELMANN, M. An Electroscope with a Point. Science Teacher, 50, n.3, p.30-32, Mar 1983.

FORBES, R. \& DIJKSTERHUIS, E. A History of Science and Technology: The Eighteenth and Nineteenth Centuries. London: Pelican Books, 1963.

FRANKLIN, A. Experiment: Right or Wrong. Cambridge: Cambridge University Press, 1990.
GAMOW, G. The Great Physicists from Galileo to Einstein. New York: Dover, 1988.

GILBERT, W. De Magnete. New York: Dover Publications Inc, 1958.

HACKMANN, W. Electricity from Glass: the History of the Frictional Electrical Machine (1600-1850). Alphen aan den Rijn, The Netherlands, Sijthoff \& Noordhoff, 1978.

HARMAN, P. Energy, Force and Matter: The Conceptual Development of Nineteenth Century Physics. Cambridge: Cambridge University Press, 1985.

HEILBRON, J. Elements of Early Modern Physics. Berkeley: University of California Press, 1982.

HOME, R. Electricity and Experimental Physics in $18^{\text {th }}$ Century Europe. Hampshire, Geat Britain: Ashgate Publishing Limited, 1992.

JEFIMENKO, O. How Can An Electroscope be Charged This Way? The Physics Teacher. 56, 1979.

LEON, G. The Story of Electricity. New York: Dover Publications Inc, 1988.

MAGIE, W. A Source Book in Physics. Cambridge: Harvard University Press, 1965.

MEDEIROS, A. \& LIMA JR, N. Identificando Pressupostos e Contextos de Validade em Experimentos com Eletroscópios. VII Encontro de Pesquisa em Ensino de Física, UFSC, Florianópolis, Março 2000.

MEYER, H. A History of Electricity and Magnetism. Boston: MIT Press, 1971.

MEYERS, ROBERT D. An Easy-to-Assemble Electroscope. Science Teacher 57, n.1, p.33-34, Jan 1990.

NERCESSIAN, N. Science 6 Philosophy. Faraday to Einstein: Constructing Meaning in Scientific Theories. Dordrecht, Netherlands: Kluwrer, 1984.

OHRINER, M. \& MACHTINGER, S. Two Electroscopes are Better Than One. The Physics Teacher 7, n. 6, p. 343-344, Sept 1969.

PLUMB, R. Triboelectricity, Journal of Chemical Education 48, p.524, 1971.

REASON, H. The Road to Modern Science. London: G. Bell \& Sons, 1959.

ROLLER, D. \& ROLLER, D. H. The Prenatal History of Electrical Science, American Journal of Physics 21, p.343-356, 1953.

ROLLER, D. The Development of the Concept of Electric Charge. In James Bryant Conant (org). Harvard Case Histories in Experimental Science. Cambridge, Massachussets: Harvard University Press, 1957.

SCARICABAROZZI, R. "Microfísica, Macrofísica e Livros-Texto". Revista de Ensino de Física, São Paulo, 5, n.1: 3/15, 1983.

SIDDONS, J. From Electroscope to Electrometer. Physics Education 18, n.1, p.39-42, Jan 1983.

SIDDONS, J. More Homespun Experiments in Physics. School Science Review 60, n.212, p.459-74, Mar 1979.

SIGAUD DE LA FOND, J. Description et Usage d'un Cabinet de Physique Expérimentale, Vol. II, Pl. XXI. Paris, 1775, 
SPENCER, G. Demonstrations in Electrostatics. American Journal of Physics 26, p.269, 1958.

STEENSON, C. Proving the Presence of Ions in Air. School Science Review 57, n.199, p.349-350, Dec 1975. STEWART, G. \& GALLAI, D. More Electrostatic Explorations. Science Scope 21, n.7, p.18-22, Apr 1998. TAYLOR, L. Physics: The Pioneer Science. New York: Dover Publications Inc, 1959.
THOMPSON, S. Elementary Lessons in Electricity and Magnetism. London: MacMillan \& Co, 1895.

TURNER, D. Makers of Science: Electricity $\&$ Magnetism. Oxford: Oxford University Press, 1927.

WIGHTMAN, W. The Growth of Scientific Ideas. Edinburgh: Oliver \& Boyd, 1951.

WHITTACKER, E. A History of the Theories of Aether E Electricity. New York: Dover Publications Inc, 1989. 